\title{
Prednisolone for the first rhinovirus-induced wheezing and 4- year asthma risk: A randomized trial
}

\author{
Annamari Koistinen $^{1}$ (D) | Minna Lukkarinen ${ }^{1,2}$ | Riitta Turunen ${ }^{1,3}$ | Tytti Vuorinen ${ }^{3}$ | \\ Tero Vahlberg $^{4}$ | Carlos A. Camargo Jr ${ }^{5,6}$ | James Gern ${ }^{7}$ | Olli Ruuskanen ${ }^{1}$ | \\ Tuomas Jartti ${ }^{1}$
}

${ }^{1}$ Department of Paediatrics and Adolescent Medicine, Turku University Hospital and University of Turku, Turku, Finland

${ }^{2}$ Research Centre of Applied and Preventive Cardiovascular Medicine, University of Turku, Turku, Finland

${ }^{3}$ Department of Clinical Virology, Turku University Hospital, Turku, Finland

${ }^{4}$ Department of Biostatistics, University of Turku and Turku University Hospital, Turku, Finland

${ }^{5}$ Department of Emergency Medicine, Harvard Medical School, Massachusetts General

Hospital, Boston, MA, USA

${ }^{6}$ Division of Rheumatology, Allergy and Immunology, Department of Medicine, Harvard Medical School, Massachusetts General Hospital, Boston, MA, USA

${ }^{7}$ The Departments of Pediatrics and Medicine, University of Wisconsin School of Medicine and Public Health, Madison, WI, USA

\section{Correspondence}

Annamari Koistinen, MD, Vinku study group, the Department of Paediatrics and Adolescent Medicine, Turku University Hospital, Turku, Finland.

Email: amkois@utu.fi

\section{Funding information}

Turku University Foundation; Suomen Akatemia, Grant/Award Number: 114034 and 132595; Sigrid Juséliuksen Säätiö; Hengityssairauksien Tutkimussäätiö; Lastentautien Tutkimussäätiö; Allergy Research Foundation in Southwest Finland; Ida Montinin Säätiö; Allergy Research Foundation; Tampereen Tuberkuloosisäätiö

\begin{abstract}
Background: Previous findings show that corticosteroid treatment during the first acute wheezing episode may reduce recurrent wheezing in children with high rhinovirus genome load at 12-month follow-up. Longer-term effects have not been investigated prospectively.

Methods: After PCR confirmation of rhinovirus from nasopharyngeal aspirate, 79 children with the first acute wheezing episode were randomized to receive orally prednisolone or placebo for 3 days. The initiation of asthma control medication before the age of 5 years was confirmed from medical record and/or from parental interview. The outcome was the time to initiation of regular asthma control medication. Interaction analysis examined rhinovirus genome load.

Results: Fifty-nine (75\%) children completed the follow-up. Asthma control medication was initiated in $40(68 \%)$ children at the median age of 20 months. Overall, prednisolone did not affect the time to initiation of asthma control medication when compared to placebo $(P=.99)$. Rhinovirus load modified the effect of prednisolone regarding the time to initiation of asthma control medication ( $P$-value for interaction=.04). In children with high rhinovirus load ( $>7000$ copies $/ \mathrm{mL}$; $n=23$ ), the risk for initiation of medication was lower in the prednisolone group compared to the placebo group $(P=.05)$. In the placebo group, asthma medication was initiated to all children with high rhinovirus load $(n=9)$ during the 14 months after the first wheezing episode.
\end{abstract}

Conclusions: Overall, prednisolone did not affect the time to initiation of asthma control medication when compared to placebo. However, prednisolone may be beneficial in first-time wheezing children whose episode was severe and associated with high rhinovirus load. (ClinicalTrials.gov, NCT00731575).

KEYWORDS

asthma, corticosteroid, prednisolone, rhinovirus, virus load, wheezing 


\section{1 | INTRODUCTION}

Systemic corticosteroid treatment has not been found effective for acute treatment or secondary prevention of asthma in young wheezing children overall. ${ }^{1-4}$ The limitation of prior studies has been the lack of subgroup analyses that might identify responsive children. ${ }^{5}$ Rhinovirus-induced wheezing is strongly associated with recurrent wheezing and asthma up to age 13 years. ${ }^{6,7}$ We have previously shown in two randomized controlled trials (RCTs) in first-time wheezing children (using both post hoc ${ }^{8}$ and prospective designs ${ }^{9}$ ) that a 3-day course of oral corticosteroid (OCS) may reduce the risk of recurrent wheezing, especially in children with high rhinovirus genome load.

Previously, using a design of RCT, the effect of OCS treatment on the wheezing recurrence in rhinovirus-affected first-time wheezing children has only been investigated up to 12 months. ${ }^{9}$ In the current analysis, our aim was to investigate the need for initiation of regular asthma control medication in the 4-year follow-up. Based on our previous findings, ${ }^{8,9}$ we hypothesized that in children with high rhinovirus genome load, the effect of OCS is likely to last beyond 12 months by reducing the need for initiation of long-term asthma control medication.

\section{2 | METHODS}

Vinku2, a randomized, placebo-controlled trial ("vinku" means wheeze in Finnish) prospectively investigated the long-term effectiveness of short course of oral prednisolone (Prednisolon ${ }^{\circledR}$, Leiras Takeda, Helsinki, Finland; during the first rhinovirus-induced wheezing episode, first dose $2 \mathrm{mg} / \mathrm{kg}$, then $2 \mathrm{mg} / \mathrm{kg} / \mathrm{d}$ in 2 doses for 3 days, maximum $60 \mathrm{mg} / \mathrm{d}$, given as minced $5 \mathrm{mg}$ tablets) until the age of five. ${ }^{9}$ Inclusion criteria were age 3-23 months, delivery at $\geq 36$ gestational weeks, first acute wheezing episode (parental report and confirmed from medical records), and nasopharyngeal aspirate positive for rhinovirus by PCR. Exclusion criteria were a chronic non-atopic illness, previous systemic or inhaled corticosteroid treatment (ICS), or a need for intensive care unit treatment. ${ }^{9}$ The study was approved by the Ethics Committee of the Turku University Hospital and was commenced only after obtaining written informed consent from the guardians.

\section{1 | Study protocol}

At study entry, patients were examined by study physician and blood samples and nasopharyngeal aspirate were taken. Children were reexamined by study physician 2 weeks, 2 months, 12 months, and 4 years after the first wheezing episode. Parents were interviewed by study physician using standardized questionnaire at study entry and 12-month and 4-year follow-ups. The electronic patient charts were reviewed regarding asthma medications, therapy adherence, and asthma symptoms for the full follow-up period. The randomization protocol was described earlier. ${ }^{9}$ The trial was double-blinded until the 12-month follow-up (ClinicalTrials.gov, NCT00731575).

\section{2 | Outcome}

The primary outcome was the time to initiation of asthma control medication until the age of 5 years. The initiation of the medication was based on the 2007 National Asthma Education and Prevention Program (NAEPP) guidelines for the diagnosis of asthma in children aged $<5$ years. ${ }^{10}$ The need for asthma control medication was defined as $\geq 4$ wheezing episodes ( $\geq 1$ diagnosed by a physician) within a year that lasted $>1$ day and affected sleep, in addition to one major risk factor (physician diagnosed atopic eczema, aeroallergen sensitization, or parental history of asthma) or two minor risk factors (wheezing apart from colds, blood eosinophil count (B-eos) $\geq 0.40 \times 10^{9} / \mathrm{L}$ or food sensitization) and/or prolonged symptoms lasting $>4$ weeks and requiring symptomatic treatment $>2$ days per week, and/or two exacerbations requiring systemic corticosteroids within 6 months. ${ }^{10}$ In some children, asthma control medication was started after the third acute wheezing episode according to the Finnish guidelines. ${ }^{11}$ The interaction analysis included the effect of rhinovirus genome load (ie, copy number) on the effectiveness of prednisolone vs placebo on the main outcome.

\section{3 | Laboratory methods}

An in-house PCR test was used for detecting rhinovirus species $A, B$, and $C$, enteroviruses, and respiratory syncytial virus (RSV) $A$ and $B$ from nasopharyngeal aspirate. ${ }^{12}$ In addition, multiplex PCR (Seeplex RV12 ACE Detection, Seegene, Seoul, Korea) was used for detecting rhinovirus, RSV A and B, adenovirus, coronavirus 229E, NL63, and HKU1, human bocavirus, human metapneumovirus, influenza $A$ and $B$, and parainfluenza virus 1-3 at the Department of Virology, University of Turku. ${ }^{12}$ Both an in-house and a commercial PCR tests were used, because according to our experience, the sensitivity of the tests, especially concerning on detection of rhinovirus, differs. Rhinovirus or RSV detected by either in-house or multiplex PCR was defined as positive. Human bocavirus was analyzed using PCR and serology. ${ }^{13}$ $\mathrm{B}$-eos and total and allergen-specific serum immunoglobulin $\mathrm{E}$ (IgE) levels were analyzed using the routine diagnostic procedures of the Central Laboratory of Turku University Hospital. Sensitization was defined as IgE antibodies to any food or aeroallergens (Phadiatop Combi $^{\circledR}$; Phadia, Uppsala, Sweden, cutoff level $\geq 0.35 \mathrm{kU} / \mathrm{L}$ ), studied in the Central Laboratory of Turku University Hospital. ${ }^{14}$ Serum 25-hydroxyvitamin D $(25(\mathrm{OH}) \mathrm{D})$ measurements were made by means of liquid chromatography-tandem mass spectrometry at Massachusetts General Hospital (Boston, MA, USA). The laboratory methods are earlier described in detail. ${ }^{9,12}$

\section{4 | Statistics}

The original power analysis was performed for 12-month, not 4-year, follow-up. ${ }^{9}$ Baseline differences in patient characteristics between treatment groups were analyzed using $t$ test (age), Mann-Whitney $U$ test (B-eos, total IgE, 25(OH)D, rhinovirus genome load, duration of breast feeding, and delay in starting the study drug), chi-square 
test (sex, any sensitization, eczema, parental allergic rhinitis, paternal smoking, pet ownership, and coinfection), or Fisher exact test (counts $<5$; admission to the ward, atopic eczema, parental asthma, maternal smoking, and virus etiology). The Cox model was used for risk of the primary outcome. It included the main effects of dichotomized rhinovirus genome load and intervention group and the interaction effect of rhinovirus genome load by intervention group. The Cox model included no covariates, as no significant differences in patient characteristics were found. Survival times were censored at the age of 5 years if the event did not occur earlier. The cutoff level for rhinovirus genome load was identified by testing different copy number levels. The threshold was selected by considering significant $P$-value for rhinovirus load vs group interaction effect similar to our previous report. ${ }^{9}$ IBM SPSS version 22 (SPSS Inc, Chicago, III, USA) was used for statistics.

\section{3 | RESULTS}

\section{1 | Study cohort}

A total of 79 children were randomized to receive prednisolone or placebo during their first acute wheezing episode. During the follow-up period, 10 children were excluded from the analysis due to insufficient follow-up time (dropouts), nine due to insufficient data about rhinovirus genome load, and one due to initiation of ICS for another reason (Figure 1). Finally, 59 (75\%) children were analyzed (inpatient:outpatient, 80\%:20\%). The excluded patients did not differ from the included patients according to age, sex, atopic characteristics, viral etiology, or any other asthma-related factors listed in Table 1 (Table S1).

\section{2 | Patient characteristics}

At study entry, the mean age of the 59 patients was 13 months (standard deviation [SD] 6 months), 18 (31\%) were sensitized, and 23 (39\%) had eczema (Table 1). Twenty children (34\%) had at least two viruses detected in their airways. Rhinovirus genome load varied across patients, with a median of 4300 copies/mL (interquartile range [IQR] 7916 000); 23 (39\%) of the patients had a rhinovirus genome load level $>7000$ copies $/ \mathrm{mL}$ (Table 2). Median delay in starting the study drug was 45 hours (IQR: 41-71). The treatment groups did not differ in any patient characteristics shown in Table 1 and Table S2. In the prednisolone group 22 (76\%) children and in the placebo group 22 (73\%) of the children received at least one OCS course during the follow-up.

\section{3 | Effectiveness of prednisolone}

Different cutoff levels for rhinovirus genome load was tested, and three different levels were noticed statistically significant (Table 2). As the differences in final results did not differ significantly depending on the cutoff (data not shown), the same level with the earlier report was used. ${ }^{9}$ Asthma control medication was initiated in 40 of 59 (68\%) children during the follow-up, in 20 of 29 (69\%) in prednisolone group, and in 20 of 30 (67\%) in placebo group. In 27 (68\%) children, the diagnosis was based on $\geq 4$ wheezing episodes in addition to risk factors, in seven children (18\%) on prolonged symptoms and requiring

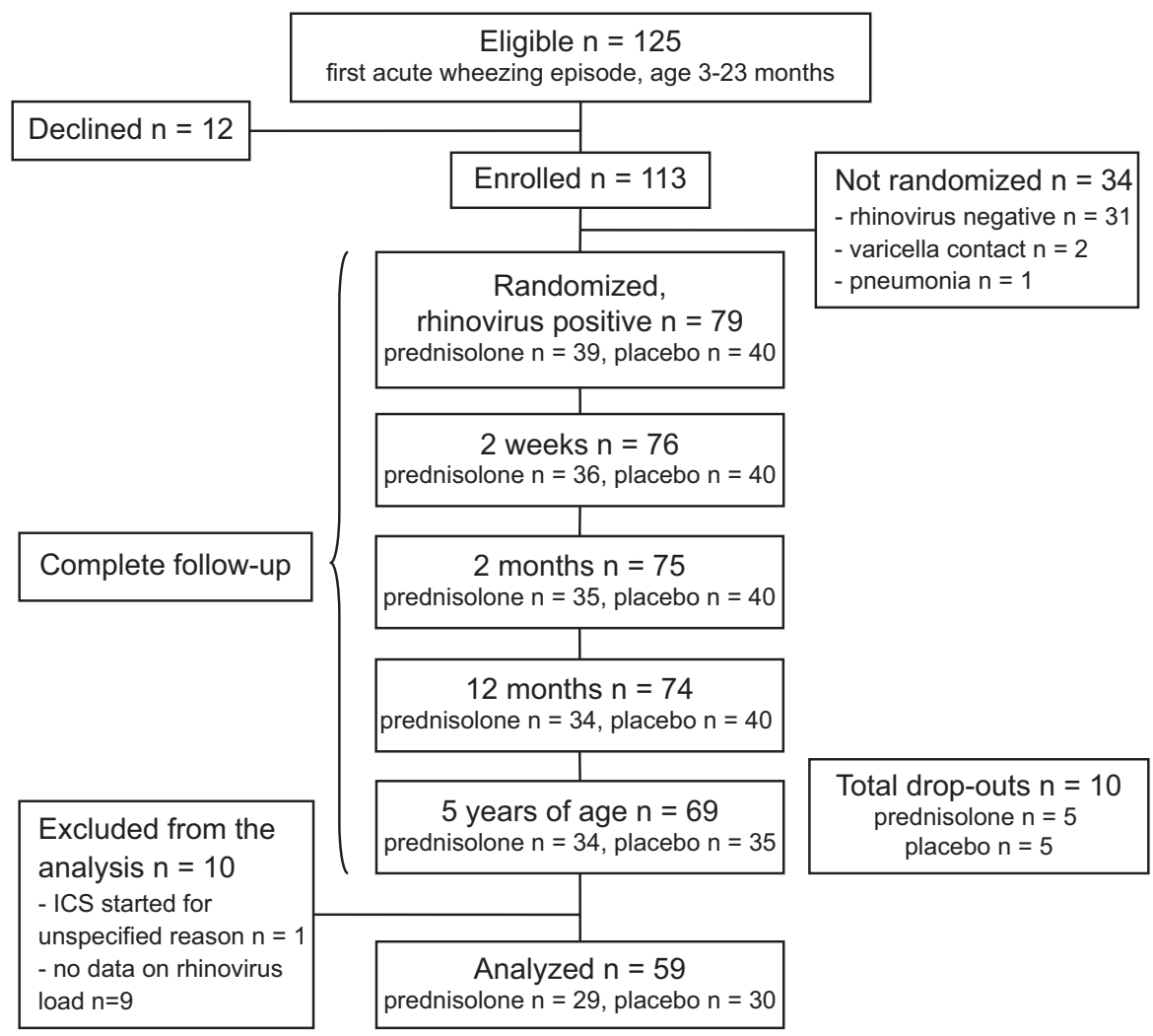


TABLE 1 Patient characteristics at study entry

\begin{tabular}{|c|c|c|}
\hline Variable & Prednisolone $(n=29)$ & Placebo $(n=30)$ \\
\hline Age, months & $13(6.9)$ & $13(5.2)$ \\
\hline Male sex, no. (\%) & $23(79)$ & $23(77)$ \\
\hline Admission to the ward, no. (\%) & $25(86)$ & $22(73)$ \\
\hline Any sensitization, no. (\%) & $7 / 28(25)$ & $9 / 29(31)$ \\
\hline B-eos, $\times 10^{9} / \mathrm{L}$ & $0.48[0.21-0.71]$ & $0.45[0.23-0.74]$ \\
\hline Eczema, no. (\%) & $12 / 28(43)$ & $11 / 29(38)$ \\
\hline Atopic eczema, no. (\%) & $7(24)$ & $4 / 29(14)$ \\
\hline Total lgE, kU/L ( $n=57)$ & $22[8.8-41]$ & $13[7.3-48]$ \\
\hline Maternal asthma, no. (\%) & $4(14)$ & $5(17)$ \\
\hline Paternal asthma, no. (\%) & $1(3)$ & $2(7)$ \\
\hline $\begin{array}{l}\text { Maternal allergic rhinitis, } \\
\text { no. (\%) }\end{array}$ & $12(41)$ & $12(40)$ \\
\hline $\begin{array}{l}\text { Paternal allergic rhinitis, } \\
\text { no. (\%) }\end{array}$ & $10(35)$ & $10(33)$ \\
\hline Maternal smoking, no. (\%) & $5(17)$ & $4(13)$ \\
\hline Paternal smoking, no. (\%) & $12(41)$ & $11(37)$ \\
\hline Pet ownership, no. ( $\mathrm{n}=58 ; \%)$ & $9(31)$ & $8(27$ \\
\hline $\begin{array}{l}\text { Total } 25(\mathrm{OH}) \mathrm{D}, \mathrm{nmol} / \mathrm{L} \\
(\mathrm{n}=57)\end{array}$ & $83(27)$ & $87(20)$ \\
\hline $25(\mathrm{OH}) \mathrm{D} 2, \mathrm{nmol} / \mathrm{L}(\mathrm{n}=57)$ & $26(25)$ & $25(2)$ \\
\hline $25(\mathrm{OH}) \mathrm{D} 3, \mathrm{nmol} / \mathrm{L}(\mathrm{n}=57)$ & $57(32)$ & $62(25)$ \\
\hline $\begin{array}{l}\text { Rhinovirus genome load, } \\
\text { copies/mL }\end{array}$ & $5800[130-47000]$ & 3000 [22-9700] \\
\hline Coinfection, no. (\%) & 9 (31) & $11(37)$ \\
\hline RSV, no. (\%) & $4(14)$ & $4(13$ \\
\hline Bocavirus, no. (\%) & $3(10)$ & $3(10$ \\
\hline Enterovirus, no. (\%) & $2(7)$ & $2(7)$ \\
\hline Influenza virus, no. (\%) & $0(0)$ & $1(3)$ \\
\hline Coronavirus, no. (\%) & $1(3)$ & $0(0)$ \\
\hline Adenovirus, no. (\%) & $1(3)$ & $1(3)$ \\
\hline Metapneumovirus, no. (\%) & $1(3)$ & $2(7)$ \\
\hline Parainfluenza virus, no. (\%) & $1(3)$ & $4(13)$ \\
\hline $\begin{array}{l}\text { Duration of breast feeding, } \\
\text { months ( } n=48)\end{array}$ & $6.0[4.0-9.0]$ & $5.0[2.0-8.0]$ \\
\hline $\begin{array}{l}\text { Delay in starting the study } \\
\text { drug after presentation for } \\
\text { acute care, hours }\end{array}$ & $45[35-48]$ & $52[42-74]$ \\
\hline
\end{tabular}

B-eos, blood eosinophil count; IgE, immunoglobulin E; RSV, respiratory syncytial virus; 25(OH)D, 25-hydroxyvitamin D.

Data are expressed as mean (standard deviation) when normally distributed and median [interquartile range] when not normally distributed, or number (\%) unless otherwise noted.

No significant differences were found between the groups when analyzed using $t$ test, Mann-Whitney $U$ test, chi-square test or Fisher exact test (counts $<5$ ) when appropriate.

symptomatic treatment, and in $23(23 \%)$ children on exacerbations requiring systemic corticosteroids. ${ }^{10}$ In five children, asthma control medication was started after the third acute wheezing episode. ${ }^{11}$ Overall, prednisolone did not affect the time to initiation of asthma control medication when compared to placebo ( $P=.99$; Figure 2). However, the level of rhinovirus genome load at study entry modified the effect of prednisolone in terms of the time to initiation of asthma control medication (rhinovirus load $x$ study drug interaction, $P=.04$, Figure 3). In children with a rhinovirus genome load of $>7000$ copies/ $\mathrm{mL}$, the risk for initiation of asthma control medication was lower in the prednisolone group $(n=14)$ compared to the placebo group $(n=9$; hazard ratio $[\mathrm{HR}]$ 0.38; 95\% confidence interval [Cl] 0.14-1.01, $P=.05$, Figure 3$)$. The asthma control medication was exclusively started to all placebo-treated children with high rhinovirus load within the subsequent 14 months after the first wheezing episode (Figure 3). Median age of the children at the time of the initiation of asthma medication was 16 months (IQR: 9-22 months). In children with a rhinovirus genome load of $\leq 7000$ copies $/ \mathrm{mL}$, no differences were found between the prednisolone $(n=15)$ and placebo groups $(n=21 ; \mathrm{HR}: 1.4,95 \% \mathrm{Cl}$ : $0.58-3.2, P=.46$, Figure 3 ). No clinically significant adverse events were reported during the acute phase.

\section{4 | DISCUSSION}

This is the first randomized placebo-controlled trial to investigate the effect of OCS treatment until preschool age in carefully characterized young children suffering from their first acute rhinovirus-induced wheezing episode. We had three main findings: First, OCS was not found to be effective overall when regarding the time to initiation of asthma control medication. Second, in the placebo group, asthma risk was high: regular asthma control medication was initiated to all children with high rhinovirus genome load during the subsequent 14 months after the first acute rhinovirus-induced wheezing episode. Third, short course of prednisolone decreased the risk of asthma control medication in children with the first severe wheezing episode caused by high rhinovirus genome load. All of these findings are in line with previous data on the increased asthma risk associated with early rhinovirus-induced wheezing. ${ }^{6-8}$

Probable explanation for the association between rhinovirus infection and risk of asthma may be that pre-existing airway inflammation in asthma-prone children predisposes to rhinovirus infection. ${ }^{15}$ Moreover, high rhinovirus genome load has been associated with more severe airway inflammation. ${ }^{16-19}$ In asthma-prone patients, interferon responses can be deficient, thus increasing virus replication and promoting type $2 \mathrm{~T}$-cell responses in respiratory epithelial cells. ${ }^{20,21}$ Moreover, rhinovirus infection may further intensify the inflammation by increasing the expression of eotaxin and interleukins 4 and 13, as well as by stimulating the immigration of eosinophils, macrophages, and neutrophils. ${ }^{22}$ Our placebo group finding of an exceptionally high risk for initiating regular asthma control medication in children with high rhinovirus genome load is consistent with these earlier findings. Nevertheless, we were surprised by the speed of asthma progression in these children.

Clinically, OCS treatment is recommended for asthma exacerbations in children, but effectiveness of OCS for the secondary prevention of asthma has not been confirmed in overall analysis of RCTs 
TABLE 2 Interaction analysis of the time to initiation of asthma control therapy, according to the study drug and different cutoffs of rhinovirus genome loads

\begin{tabular}{|c|c|c|c|c|}
\hline $\begin{array}{l}\text { Cutoff for rhinovirus } \\
\text { genome load } / \mathrm{mL}\end{array}$ & $\begin{array}{l}\text { No. }(\%) \text { of patients with } \\
\text { rhinovirus genome load >cutoff }\end{array}$ & $\begin{array}{l}P \text {-value for } \\
\text { interaction }\end{array}$ & $\begin{array}{l}\mathrm{HR}(95 \% \mathrm{CI}) \text { for } \leq \text { cutoff value, } \\
\text { prednisolone vs placebo }\end{array}$ & $\begin{array}{l}\text { HR }(95 \% \mathrm{CI}) \text { for }>\text { cutoff value, } \\
\text { prednisolone vs placebo }\end{array}$ \\
\hline 3000 & $31 / 59(55)$ & .87 & $1.79(.65,4.94)$ & $0.60(.27,1.31)$ \\
\hline 5000 & $28 / 59(48)$ & .04 & $1.68(.68,4.14)$ & $0.46(.13,1.12)$ \\
\hline 7000 & 23/59 (39) & .04 & $1.38(.58,3.25)$ & $0.38(.14,1.01)$ \\
\hline 9000 & $21 / 59$ (36) & .02 & $1.39(.61,3.15)$ & $0.33(.12, .95)$ \\
\hline 11000 & $19 / 59$ (32) & .06 & $1.23(.56,2.72)$ & $0.36(.12,1.11)$ \\
\hline
\end{tabular}

$\mathrm{HR}$, hazard ratio; $\mathrm{Cl}$, confidence interval. The statistically significant cut-off values are marked in bold.

concerning children suffering from early wheezing episode. ${ }^{1,4}$ In our earlier post hoc analysis of the Vinku study, the children with the first rhinovirus-induced wheezing episode and/or eczema benefitted from prednisolone treatment in terms of lower risk for recurrence of wheezing in 7-year follow-up. ${ }^{8}$ Unfortunately, quantitative PCR was not used in this earlier study. By contrast, the RCT of Vinku2 did quantify virus genomic load; in an earlier analysis, we report that prednisolone treatment reduced the recurrence of wheezing in a group of children with a rhinovirus genome load of $>7000$ copies $/ \mathrm{mL}$ in a 12 month follow-up. ${ }^{9}$ Our current 4-year results are in line with these previous findings and support the view that the risk of asthma can be reduced when high-risk children are identified early and treated with OCS. OCS is likely to downregulate asthma-associated inflammatory pathways by decreasing the transcription of many inflammatory genes and/or their transcription factors and increasing the expression of various anti-inflammatory genes. ${ }^{4,23}$ Furthermore, starting the acute care early may be important, as rhinovirus load peaks early in infection. ${ }^{24}$

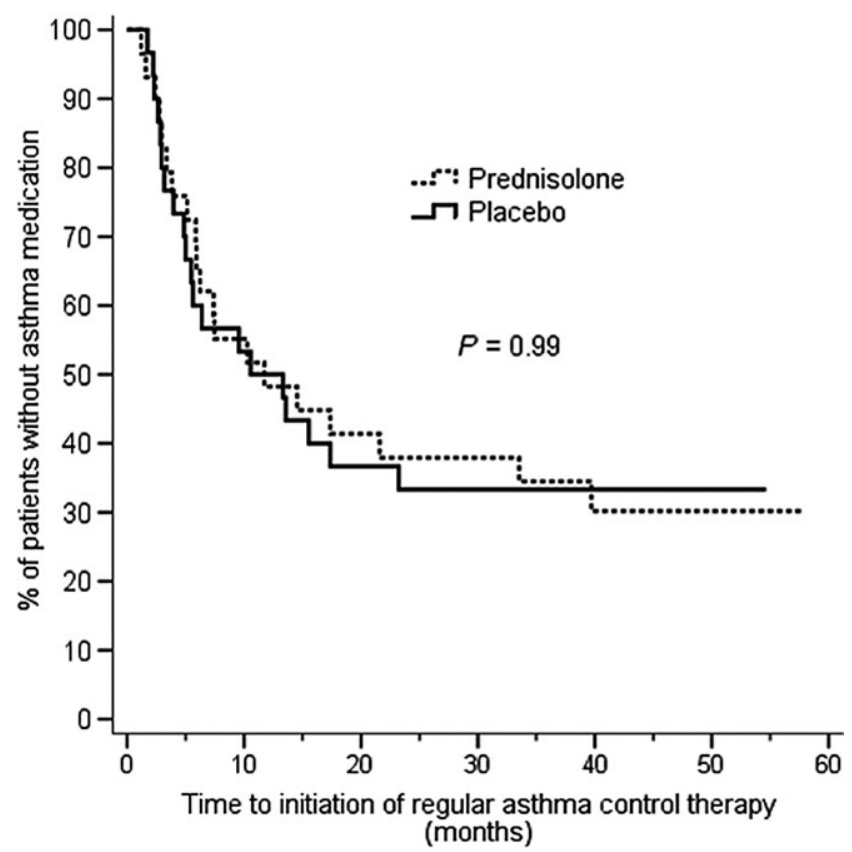

FIGURE 2 The time to initiation of asthma control medication in children randomized to receive prednisolone or placebo for the first rhinovirus-induced wheezing episode. No difference was found in overall analysis
It is important to concentrate on finding the phenotype of young wheezing children that could most likely benefit from early OCS treatment. Dumas et al. ${ }^{5}$ used a clustering approach and identified several phenotypes for severe bronchiolitis. We speculate that those with rhinovirus etiology and/or early atopic characteristic (cluster A) would most likely benefit from early intervention trials with antiinflammatory medication to prevent recurrent wheezing and asthma. Our study population, especially those with high rhinovirus load, most likely represent the cluster $A$.

Most ${ }^{9,16-19}$ but not all ${ }^{25,26}$ previous studies have shown the higher rhinovirus genome load to be associated with more severe and/or longer duration of acute lower respiratory illness. There are no previous data concerning the long-term outcomes beyond 12 months. ${ }^{9}$ We used

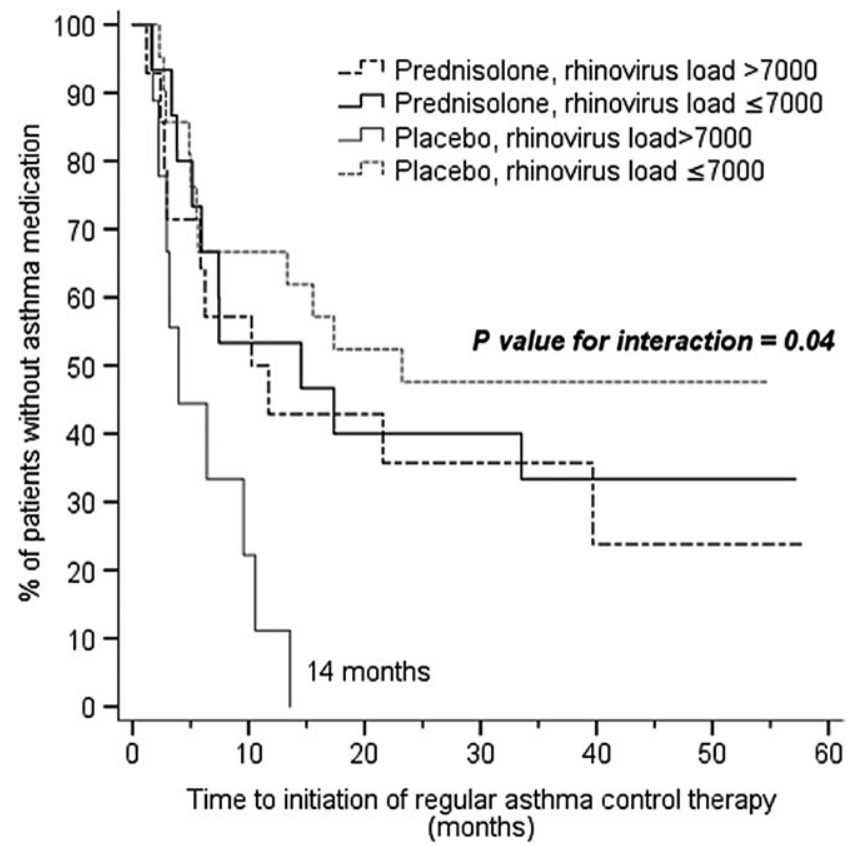

FIGURE 3 The time to initiation of asthma control medication in children randomized to receive prednisolone or placebo for the first rhinovirus-induced wheezing episode. Data are represented according to the rhinovirus genome load. Children with a rhinovirus genome load of $>7000$ copies $/ \mathrm{mL}$ had longer time to initiation of asthma control medication in prednisolone group when compared with the placebo group. In the placebo group, asthma medication was initiated to all children with high rhinovirus genome load $(n=9)$ during the 14 mo after the first wheezing episode 
more sensitive PCR (real-time PCR) compared to our previous study (conventional PCR and liquid hybridization), ${ }^{8}$ which also allows quantification of rhinovirus genome load. Here, we also used highly concentrated samples, while previous studies that did not find a relationship between viral shedding and outcomes ${ }^{25,26}$ used nasal wash samples to estimate genome load. These differences in methodology may explain apparent discrepancies between our results and those earlier studies.

The strengths of the study include careful characterization of the patients and RCT design although blinding was opened (as planned) for the 12-month report. ${ }^{9}$ However, our study has some limitations. The sample size was small but large enough to generate statistically significant results consistent with our previous studies. ${ }^{89}$ Most patients were hospitalized which raises questions about the generalizability of our results to outpatients or mild wheezing illness. ${ }^{27}$ Rhinovirus diagnostics caused a delay in administration of the study drug which could have contributed to the lack of effectiveness of prednisolone in overall rhinovirus analysis (in addition to more sensitive PCR). In our earlier post hoc analysis with no delay in initiation of study drug and no quantitative rhinovirus detection, prednisolone was found effective in all children with rhinovirus and/or eczema. ${ }^{8,28}$ The inflammatory profiling of T helper 1 and T helper 2 mediators in different subgroups would increase the interest of our findings but we did not do the profiling. Moreover, there were many cutoff levels of rhinovirus genome load with significant $P$-value. In this study, we made a decision to be in line with the earlier follow-up. ${ }^{9}$

In summary, early systemic short-course prednisolone treatment may be beneficial in reducing the risk for asthma control medication during the first 5 years in first-time wheezing preschool children whose episode was severe and associated with high rhinovirus genome load. The results call attention to different phenotypes of bronchiolitis and early wheezing, ${ }^{5}$ which are likely to respond differently to different therapies. The natural course of asthma inception may be modifiable when high-risk children are identified early, even at the time of the first wheezing episode, and targeted with an effective intervention strategy.

\section{ACKNOWLEDGMENTS}

We thank biomedical laboratory scientist Heidi Jokinen from Department of Clinical Virology, Turku University Hospital, Turku, Finland, for virus analyses and Tiina Peromaa from Research Centre of Applied and Preventive Cardiovascular Medicine, University of Turku, Turku, Finland, for her work as a study nurse.

\section{REFERENCES}

1. Jartti T, Vanto T, Heikkinen T, Ruuskanen O. Systemic glucocorticoids in childhood expiratory wheezing: relation between age and viral etiology with efficacy. Pediatr Infect Dis J. 2002;21:873-878.

2. Oommen A, Lambert PC, Grigg J. Efficacy of a short course of parentinitiated oral prednisolone for viral wheeze in children aged 1-5 years: randomised controlled trial. Lancet. 2003;362:1433-1438.

3. Panickar J, Lakhanpaul M, Lambert PC, et al. Oral prednisolone for preschool children with acute virus-induced wheezing. N Engl J Med. 2009;360:329-338

4. de Benedictis FM, Bush A. Corticosteroids in respiratory diseases in children. Am J Respir Crit Care Med. 2012;185:12-23.
5. Dumas O, Mansbach JM, Jartti T, et al. A clustering approach to identify severe bronchiolitis profiles in children. Thorax. 2016;71:712.

6. Midulla F, Nicolai A, Ferrara M, et al. Recurrent wheezing 36 months after bronchiolitis is associated with rhinovirus infections and blood eosinophilia. Acta Paediatr. 2014;103:1094-1099.

7. Rubner FJ, Jackson DJ, Evans MD, et al. Early life rhinovirus wheezing, allergic sensitization, and asthma risk at adolescence. J Allergy Clin Immunol. 2017;139:501-507.

8. Lukkarinen $\mathrm{M}$, Lukkarinen $\mathrm{H}$, Lehtinen $\mathrm{P}$, et al. Prednisolone reduces recurrent wheezing after first rhinovirus wheeze: a 7-year follow-up. Pediatr Allergy Immunol. 2013;24:237-243.

9. Jartti T, Nieminen R, Vuorinen T, et al. Short- and long-term efficacy of prednisolone for first acute rhinovirus-induced wheezing episode. J Allergy Clin Immunol. 2015;135:691-698.

10. National Heart Lung and Blood Institute. Expert panel report 3: Guidelines for the diagnosis and management of asthma - Full report; 2007. http://www.nhlbi.nih.gov/health-pro/guidelines/current/asthma-guidelines. Accessed August 28, 2007.

11. Working group set up by the Finnish Medical Society Duodecim and the Finnish Cardiac Society, Helsinki. Current Care Guidelines: Asthma; 2012. www.kaypahoito.fi. Accessed September 24, 2012.

12. Turunen R, Koistinen A, Vuorinen $\mathrm{T}$, et al. The first wheezing episode: respiratory virus etiology, atopic characteristics, and illness severity. Pediatr Allergy Immunol. 2014;25:796-803.

13. Söderlund-Venermo M, Lahtinen A, Jartti T, et al. Clinical assessment and improved diagnosis of bocavirus-induced wheezing in children, Finland. Emerg Infect Dis. 2009;15:1423-1430.

14. Jartti T, Lehtinen P, Vuorinen T, Ruuskanen O. Bronchiolitis: age and previous wheezing episodes are linked to viral etiology and atopic characteristics. Pediatr Infect Dis J. 2009;28:311-317.

15. Jakiela B, Brockman-Schneider R, Amineva S, Lee WM, Gern JE. Basal cells of differentiated bronchial epithelium are more susceptible to rhinovirus infection. Am J Respir Cell Mol Biol. 2008;38:517-523.

16. Takeyama A, Hashimoto K, Sato M, et al. Rhinovirus load and disease severity in children with lower respiratory tract infections. J Med Virol. 2012;84:1135-1142.

17. Esposito S, Daleno C, Scala A, et al. Impact of rhinovirus nasopharyngeal viral load and viremia on severity of respiratory infections in children. Eur J Clin Microbiol Infect Dis. 2014;33:41-48.

18. Xiao Q, Zheng S, Zhou L, et al. Impact of human rhinovirus types and viral load on the severity of illness in hospitalized children With lower respiratory tract infections. Pediatr Infect Dis J. 2015;34:1187-1192.

19. Bruning $A H$, Thomas $X V$, van der Linden $L$, et al. Clinical, virological and epidemiological characteristics of rhinovirus infections in early childhood: a comparison between non-hospitalised and hospitalised children. J Clin Virol. 2015;73:120-126.

20. Baraldo S, Contoli M, Bazzan E, et al. Deficient antiviral immune responses in childhood: distinct roles of atopy and asthma. J Allergy Clin Immunol. 2012;130:1307-1314.

21. Contoli M, Ito K, Padovani A, et al. Th2 cytokines impair innate immune responses to rhinovirus in respiratory epithelial cells. Allergy. 2015;70:910-920.

22. Stone CA Jr, Miller EK. Understanding the association of human rhinovirus with asthma. Clin Vaccine Immunol. 2015;23:6-10.

23. Stellato C. Glucocorticoid actions on airway epithelial responses in immunity: functional outcomes and molecular targets. J Allergy Clin Immunol. 2007;120:1247-1263.

24. Kennedy JL, Shaker M, McMeen V, et al. Comparison of viral load in individuals with and without asthma during infections with rhinovirus. Am J Respir Crit Care Med. 2014;189:532-539.

25. Miller EK, Hernandez JZ, Wimmenauer V, et al. A mechanistic role for type III IFN- $\lambda 1$ in asthma exacerbations mediated by human rhinoviruses. Am J Respir Crit Care Med. 2012;185:508-516.

26. Jartti T, Hasegawa K, Mansbach JM, Piedra PA, Camargo CA Jr. Rhinovirus-induced bronchiolitis: lack of association between virus 
genomic load and short-term outcomes. J Allergy Clin Immunol. 2015;136:509-512.

27. Bønnelykke K, Vissing NH, Sevelsted A, Johnston SL, Bisgaard $\mathrm{H}$. Association between respiratory infections in early life and later asthma is independent of virus type. J Allergy Clin Immunol. 2015;136:81-86.

28. Lukkarinen $M$, Vuorinen $T$, Lehtinen $P$, Ruuskanen $O$, Jartti $T$. Sensitization at the first wheezing episode increases risk for longterm asthma therapy. Pediatr Allergy Immunol. 2015;26:687-691.

\section{SUPPORTING INFORMATION}

Additional Supporting Information may be found online in the supporting information tab for this article.
How to cite this article: Koistinen A, Lukkarinen M, Turunen $\mathrm{R}$, et al. Prednisolone for the first rhinovirusinduced wheezing and 4-year asthma risk: $\mathrm{A}$ randomized trial. Pediatr Allergy Immunol. 2017;28:

557-563. https://doi.org/10.1111/pai.12749 